\title{
Digging beneath the surface: incipient nest characteristics across three species of harvester ant that differ in colony founding strategy
}

\author{
B. L. Enzmann • P. Nonacs
}

Received: 16 March 2009/Revised: 17 November 2009/Accepted: 25 November 2009/Published online: 20 December 2009

(C) The Author(s) 2009. This article is published with open access at Springerlink.com

\begin{abstract}
Ants exhibit a size-associated colony founding trait that is characterized by the degree to which foundresses rely on internal reserves to raise their first brood of workers (claustrality). The reliance on stored reserves is positively correlated with degree of claustrality (claustral $>$ facultative $>$ semi-claustral) and is variable across species of Pogonomyrmex harvester ants. Three species of harvester ant foundresses that differ in degree of claustrality were observed initiating nests under laboratory conditions over 2 years. P. rugosus is fully claustral, P. salinus is facultative, and P. californicus is semi-claustral. Across species, degree of claustrality was positively associated with mean digging rate and nest depth over the first 3 days of nest initiation, total nest depth, and degree of nest closure. Branching and abundance of peripheral nodes were higher in semi-claustral and facultative nests than in claustral nests. The facultative species dug for the longest time and achieved the greatest tunnel length. Within each species, there were trends associating mass with digging rate, but these were not consistent in all species. There were no intraspecific trends of mass with nest depth. Also within species, a foundress's mass did not affect her tendency to open or close her nest. These results reveal degree of claustrality is correlated across species with several nest initiation characteristics that together may represent different colony founding syndromes.
\end{abstract}

\footnotetext{
B. L. Enzmann $(\bowtie) \cdot$ P. Nonacs

Department of Ecology and Evolutionary Biology,

University of California, Los Angeles,

621 Charles E. Young Drive South,

Los Angeles, CA 90095, USA

e-mail: benzmann@ucla.edu

P. Nonacs

e-mail: pnonacs@biology.ucla.edu
}

Keywords Pogonomyrmex - Harvester ants . Colony founding $\cdot$ Nest structure $\cdot$ Claustrality

\section{Introduction}

Body size is a ubiquitous life history trait associated with reproduction (Roff, 1992; Stearns, 1992). The affect of body size on reproductive strategy is particularly apparent in ants, where a wide variety of strategies exist. In Pogonomyrmex harvester ants, each colony undergoes an annual nuptial flight, where gynes and males leave the nest and mate following either a monsoonal rain or photoperiod cue (Hölldobler and Wilson, 1990; Johnson, 2000b). After the flight, gynes (now termed foundresses) disperse and most species dig out nests independently (haplometrotic). This type of founding differs from swarming types of social insects (e.g., honey bees) in that there are no workers to help with nest initiation. Thus, reproductive success is solely dependent upon the success of the foundress at initiating a nest. Harvester ant foundresses are subject to predation and desiccation risks (Hölldobler and Wilson, 1990), resulting in a high mortality rate (Hölldobler and Wilson, 1990; Wiernasz and Cole, 2003) that may reach 99\% (Gordon and Kulig, 1996; Johnson, 2001; Pfennig, 1995). This indicates that there is likely high selective pressure on foundresses during colony initiation.

There is considerable evidence that foundress size affects the early stages of founding in ants. Species that found independently tend to be larger than dependentfounding species (Rüppell and Heinze, 1999). Within independently founding species, foundresses that found singly are larger than those that found multiply, as seen in Messor pergandei (Cahan and Rissing, 2005) and other species (Kikuchi et al., 1999; McInnes and Tschinkel, 
1995; Rüppell et al., 1998). Even within founding pairs, larger foundresses have been observed to succeed more often (Nonacs, 1990). In field colonies of P. occidentalis, large body size results in higher survival rate of foundresses during initial colony establishment (Wiernasz and Cole, 2003). Foundresses of $P$. rugosus exhibit higher survivorship relative to their smaller sister species, $P$. barbatus under xeric conditions (Johnson, 1998). These studies all suggest that large foundress size may confer a benefit to colony founding success in ants. At the other extreme, small size of foundresses may allow faster brood production given higher mass-specific metabolic rates, as seen in P. barbatus relative to P. rugosus (Johnson, 1998, $2000 \mathrm{~b}$ ) and a greater number of first workers (Johnson, 2002).

Pogonomyrmex harvester ants exhibit a variation in colony founding strategy that is characterized by body size and degree of reliance on internal reserves to raise their first brood of workers (nanitics). This type of variation is referred to here as claustrality. Fully claustral foundresses are large in size and raise nanitics using only stored reserves (Hölldobler and Wilson, 1990). This strategy is predominant in derived ant subfamilies (Brown and Bonhoeffer, 2003; Hölldobler and Wilson, 1990; Johnson, 2006a) and also occurs in some other social insects (e.g., termites, Adam and Mitchell, 2009). Claustral ant foundresses isolate themselves after nest initiation and tend to plug the nest entrance with soil. Alternatively, semiclaustral foundresses are smaller in size and must forage to obtain sufficient nutrients to raise nanitics. These foundresses typically leave nest entrances open. In the middle of the claustrality continuum are facultative species where gynes may or may not be able to produce brood without foraging (Anderson and Keyel, 2006; Brown and Bonhoeffer, 2003; Johnson, 2002). Various costs and benefits related to claustrality have been explored, with the most apparent benefit to claustral foundresses being that their larger stored reserve allows avoidance of foraging risks while the benefit to semi-claustral foundresses is greater brood number (Johnson, 2002, 2006a).

Degree of claustrality and size within species are likely relevant to foundress nest construction in independently founding species, though this aspect has not been explored. In particular, founding strategy across species and size within species may interact with abiotic factors (e.g., water availability and temperature) to shape the evolution of incipient nest characteristics. For example, larger individuals may dig faster per unit time and achieve greater tunnel depth and/or length, which could be advantageous in hot and arid habitats. Semi-claustral foundresses that forage may have a different nest construction than claustral foundresses given that they also need to allocate energy toward foraging. Energy conservation can be especially pressing given that foundresses have already experienced a costly nuptial flight and dispersal (Passera and Keller, 1990; Wheeler and Buck, 1996) and also must produce eggs.

Here, we investigate whether degree of claustrality across species and size within species affect a number of critical variables during nest founding. Specifically, the following predictions were tested:

1. Nest depth will correlate positively with degree of claustrality across species and with mass within species.

2. The network topology of nests will show distinctive differences across species that differ in degree of claustrality.

3. Tunnel length will correlate positively with degree of claustrality across species.

4. Digging rate will correlate positively with degree of claustrality across species and with mass within species.

5. Nest-plugging behavior will correlate positively with degree of claustrality (semi-claustral foundresses keep nest entrances open, claustral foundresses will keep them closed, and facultative foundresses will exhibit either behavior depending on their size).

\section{Methods}

\section{Collection and set-up}

Three species of Pogonomyrmex foundresses were collected after their summer nuptial flights. $P$. californicus is a small semi-claustral species (mean wet mass $13.15 \mathrm{mg} \pm 1.98$, $N=30$ ). Foundresses were collected in Pine Valley, California (July 2007 and 2008). P. salinus foundresses are facultative (Anderson and Keyel, 2006) and intermediate in size (mean wet mass $15.48 \pm 1.53, N=36$ ) and were collected at the Sierra Nevada Aquatic Research Laboratory, Mammoth Lakes (August 2005 and 2008). Lastly, $P$. rugosus foundresses are large and fully claustral (mean wet mass $46.92 \pm 5.42, N=42$ ) and were collected in Tucson, AZ in August 2007 and near Phoenix in July 2008.

Individual foundresses were placed inside enclosures (Johnson, 2003) consisting of two $8.8 \mathrm{~cm} \times 25.4 \mathrm{~cm}$ sheets of plexiglass or glass separated by a perimeter of wood $(8.8 \mathrm{~cm} \times 21.6 \mathrm{~cm})$. A $0.31-\mathrm{cm}$ wood depth was used for the two smaller species (P. salinus, $P$. californicus) and a $0.6-\mathrm{cm}$ wood depth was used for the larger $P$. rugosus. The reason why this was done was to allow for freedom of movement for all foundresses (an enclosure that is too narrow could have hindered digging ability). Enclosures were filled with $17.75-19 \mathrm{~cm}$ of sieved soil and moistened by pouring de-ionized water on the top of the nest until it 
diffused throughout the entire area. All farms were kept at $30^{\circ} \mathrm{C}$ on a 12-h photoperiod and watered to keep soil slightly moist when necessary. Since $P$. californicus and $P$. salinus require external food sources (semi-claustral and facultative, respectively), foundresses of these species were supplied with Kentucky Bluegrass seeds (Poa pratensis) (Johnson, 2002) after digging behavior ceased.

\section{Digging and topological measurements}

Digging achieved per day (24-h period) was measured by tracing new tunnel length directly onto enclosures each day until digging behavior ceased. Marked lines were then measured with a flexible string to the nearest quarter centimeter. Foundresses that did not dig past the first day (day 0 ) were excluded from rate comparisons. Foundresses that died during this period were also excluded from analyses.

Nest depth was measured by calculating the distance from the top of the soil to the greatest depth reached after days $1,2,3$, and total days that foundresses dug. Data for each species were square root transformed to produce normality and were combined across years, though depth measurements were not available for $P$. salinus during 2005. Network topology was quantified by measuring the degree of centrality $\left(k_{i}\right)$ of each node $i$ in nests. This measure describes the number of edges ( $E$ tunnels) incident upon a node ( $N$ intersections between tunnels, nest entrances, and dead ends) and thus may be used to describe the type and amount of branching in a nest (Buhl et al., 2004, 2006). The number of nodes and edges were counted to calculate the average node degree $(K)$ per nest using the formula: $K=2 E / N$ (Croft et al., 2008). The average $K$ across all nests of each species was then calculated. The number of peripheral nodes $\left(k_{i}=1\right.$, nest entrances and dead ends) relative to internal nodes $\left(k_{i}>2\right.$, intersections) was compared across species and the measures of $E, N$, and total tunnel length were also used for other topological measurements.

Nest entrance-plugging behavior

Plugging and unplugging of nest entrance holes with dirt was variable in all three species, so this behavior was tracked throughout the colony founding period of all species. Observations were taken every 2-3 days.

\section{Statistics}

Analysis of variance (ANOVA) was used for across species comparisons where data were normally distributed, and Tukey HD post hoc tests were used for pairwise comparisons. Kruskal-Wallis tests were used for across species comparisons where data did not meet normality and/or equal variance assumptions, and Mann-Whitney $U$ tests with Bonferroni correction were used for pairwise comparisons. Linear regressions were used for all intraspecific comparisons.

\section{Results}

Nest structure and topology

Nest structure varied substantially, with branching patterns and nest depths visually distinguishable across species (Fig. 1). Nest depth was positively correlated with degree of claustrality (claustral $>$ facultative $>$ semi-claustral) across the three species after days 1,2, 3 and for total depth (Table 1). Differences were significant between $P$. californicus and $P$. rugosus and $P$. salinus and $P$. rugosus on day 1 (ANOVA: $F=73.9, d f=84$, post hoc: $P<0.001 P$. californicus \& P. rugosus, P. salinus \& P. rugosus). For days 2 , 3 , and total depth differences were significant across all three species (Day 2, ANOVA $F=92.85, d f=82, P<0.05$, post hoc: $P<0.006$ all comparisons; Day 3, Kruskal-Wallis: $\chi^{2}=57.6, d f=2, P<0.001$, post hoc: $P<0.001$ all comparisons; Total depth, Kruskal-Wallis: $\chi^{2}=47.54$, $d f=2, P>0.001$, post hoc: $P<0.005$ all comparisons). However, no relationship was found between nest depth and foundress mass within any of the three species.

$P$. californicus foundresses dug the shallowest nests, ranging from 1.5 to $14.75 \mathrm{~cm}$ (mean $5.10 \pm 3.21 \mathrm{~cm}$, $N=23$ ) that never reached the bottom barrier of the enclosure. Nests were highly branched and sometimes had a U-shape with two entrances. P. californicus nests also had the greatest abundance of nodes relative to nest length, significantly more than $P$. rugosus (Kruskal-Wallis: $\chi^{2}=32.44, \quad d f=2, \quad P<0.001$, post hoc: $P<0.001$ $P$. californicus \& P. rugosus, Table 1). The frequency of peripheral nodes relative to internal nodes was significantly greater for $P$. californicus than for both $P$. salinus and $P$. rugosus (Kruskal-Wallis: $\chi^{2}=12.46, \quad d f=2, \quad P=$ 0.002 , post hoc: $P<0.01 P$. californicus \& $P$. salinus, P. californicus \& P. rugosus, Table 1). Average node degree across nests for this species was also the lowest, reflecting the high abundance of peripheral nodes (Fig. 1; Table 1). The number of branches grew linearly with, but slightly slower than the number of nodes (Fig. 2).

$P$. salinus foundresses dug intermediate nests, ranging from 2.50 to $17.75 \mathrm{~cm}$ (mean $13.46 \pm 5.02 \mathrm{~cm}, N=18$ ). Thirty percent $(6 / 20)$ reached the bottom barrier (but none by the first 3 days) and 20\% (4/20) reached their maximum depth by day 3 . Like $P$. californicus, nests were highly branched with numerous horizontal tunnels with an intermediate amount of nodes relative to nest length, but significantly more than $P$. rugosus (Kruskal-Wallis: 


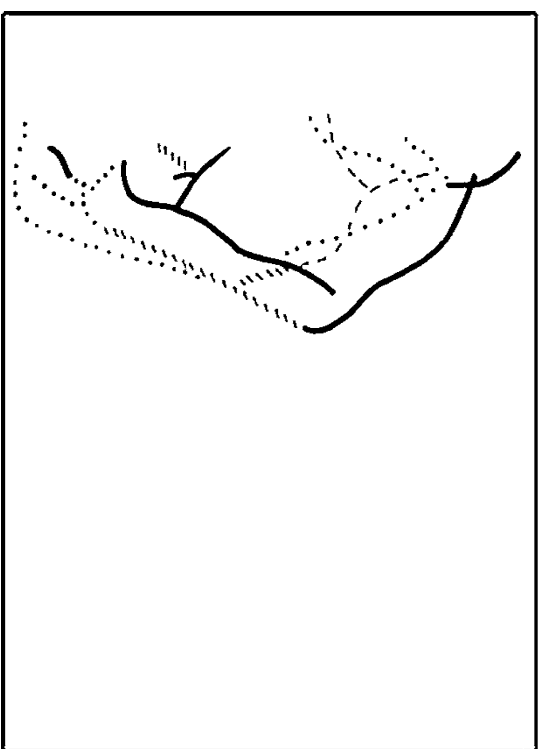

a

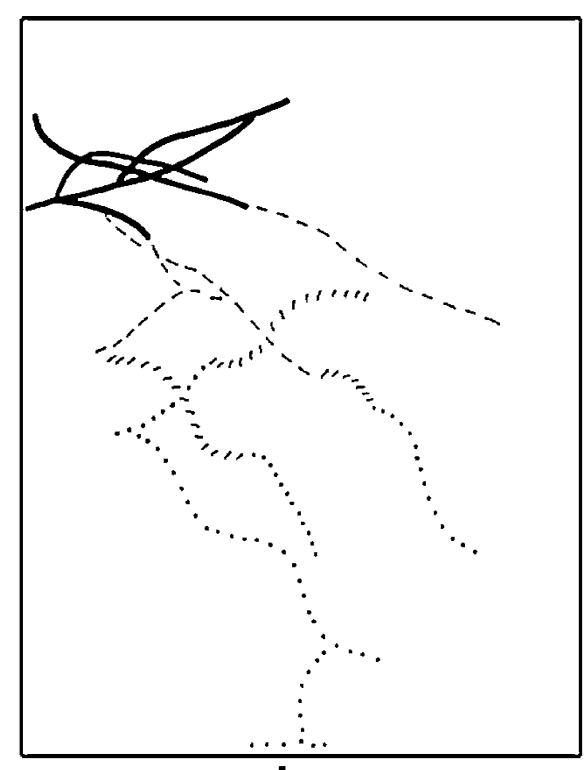

b

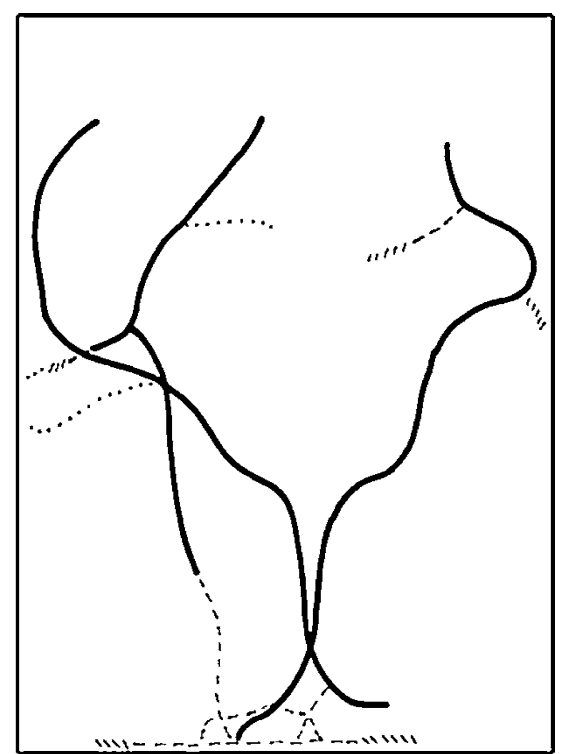

C
Fig. 1 Example tracings of a $P$. californicus, b $P$. salinus, and $\mathbf{c} P$. rugosus nests. Each panel is an overlay of three nests. Amount dug: solid line day 1 , dashed line day 2 , hashed line day 3 , dotted line remaining days. P. californicus dug shallow, branched nests and usually reached maximum depth by day 3 . P. salinus dug intermediate, branched nests and typically did not reach maximum depth by day 3. P. rugosus dug deep, vertical nests and often hit the bottom barrier by day 3
Table 1 Mean \pm SE for nest depth, digging rate, topological measurements, total amount dug, number of days spent digging, and percent of nests entrances left open for $P$. californicus, $P$. salinus, and $P$. rugosus

Sample sizes are in parentheses

\begin{tabular}{lccc}
\hline Nest characteristic & P. californicus & P. salinus & P. rugosus \\
\hline Depth $(\mathrm{cm})$ & & & \\
Day 1 & $2.67 \pm 0.29(23)$ & $3.69 \pm 0.35(18)$ & $9.32 \pm 0.55(42)$ \\
Day 2 & $4.20 \pm 0.52$ & $6.61 \pm 0.70$ & $14.32 \pm 0.52$ \\
Day 3 & $4.55 \pm 0.59$ & $9.31 \pm 0.97$ & $16.26 \pm 0.45$ \\
Total & $5.10 \pm 0.67$ & $13.46 \pm 1.18$ & $17.11 \pm 0.35$ \\
Digging rate (cm/day) & & & \\
Days 0-1 & $5.23 \pm 0.53(31)$ & $10.67 \pm 0.52(36)$ & $14.75 \pm 0.83(40)$ \\
Days 1-2 & $3.61 \pm 0.51$ & $7.70 \pm 0.55$ & $9.40 \pm 0.54$ \\
Days 2-3 & $1.74 \pm 0.27$ & $6.12 \pm 0.54$ & $5.25 \pm 0.54$ \\
\# Nodes & $11.30 \pm 6.35(23)$ & $12 \pm 4.90(18)$ & $8.41 \pm 2.95(39)$ \\
\# Edges & $9.22 \pm 5.85$ & $11.33 \pm 4.90$ & $7.59 \pm 2.98$ \\
N/E & $1.27 \pm 0.23$ & $1.09 \pm 0.11$ & $1.16 \pm 0.22$ \\
Average $K$ & $1.61 \pm 0.23$ & $1.86 \pm 0.19$ & $1.77 \pm 0.26$ \\
\# Peripheral nodes $(P)$ & $7.57 \pm 3.62$ & $6.94 \pm 2.46$ & $5.03 \pm 1.40$ \\
\# Internal nodes $(I)$ & $4.00 \pm 3.52$ & $5.17 \pm 2.38$ & $3.39 \pm 1.53$ \\
Freq $(P) /$ freq $(I)$ & $2.72 \pm 1.76$ & $1.54 \pm 0.57$ & $1.63 \pm 0.64$ \\
\# Nodes/tunnel length & $0.60 \pm 0.33$ & $0.36 \pm 0.11$ & $0.23 \pm 0.07$ \\
Amount dug (cm) & $17.95 \pm 1.91(25)$ & $54.88 \pm 3.29(28)$ & $35.93 \pm 1.28(39)$ \\
Days spent digging & $8.5 \pm 0.77(20)$ & $15.23 \pm 1.0(32)$ & $7.13 \pm 0.67(32)$ \\
Nest entrance open & $91 \%$ & $60.5 \%$ & $4.5 \%$ \\
\hline
\end{tabular}

$\chi^{2}=32.44, d f=2, P<0.001$, post hoc: $P<0.001 P$. salinus \& P. rugosus, Table 1). Even though they had an intermediate amount of peripheral nodes, their high frequency of internal nodes gave the lowest peripheral: internal node ratio out of the three species (Table 1). This means that this species has relatively more internal nodes and a higher average node degree than the other species, significantly higher than $P$. californicus (Kruskal-Wallis: $\chi^{2}=16.71, \quad d f=2, \quad P<0.001$, post hoc: $P<0.001$ $P$. californicus \& P. salinus, Fig. 1; Table 1). The number 


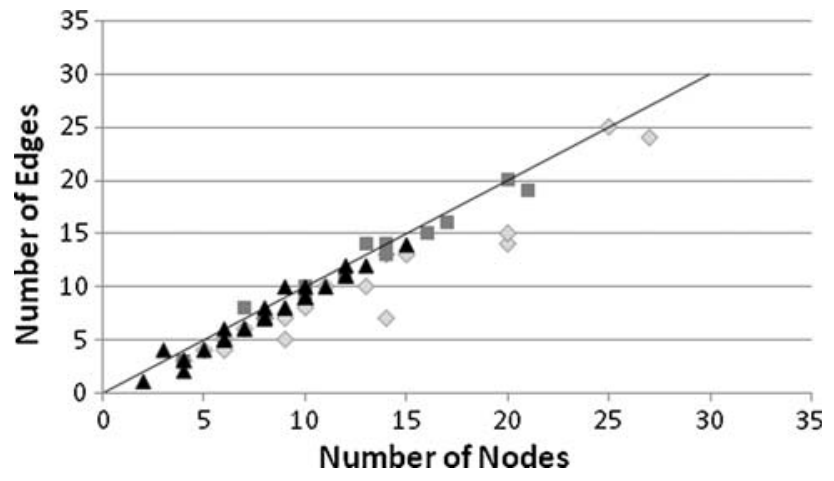

Fig. 2 Linear relationship between the number of nodes and edges for $P$. californicus (light gray diamonds), P. salinus (dark gray squares), and $P$. rugosus (black triangles). Least squares linear trend lines fit data the best for all species, P. californicus: slope 0.89 , $R^{2}=0.92 ;$ P. salinus: slope $0.98, R^{2}=0.98 ;$ P. rugosus: slope 0.99 , $R^{2}=0.97$. A trend line with a slope of 1 is indicated

of branches grew nearly isometrically with the number of nodes (Fig. 2).

$P$. rugosus foundresses dug very deep nests, with depths ranging from 6.25 to $19.0 \mathrm{~cm}$ (mean $17.11 \pm 2.27 \mathrm{~cm}$, $N=42)$. Eighty-three percent $(35 / 42)$ reached the bottom barrier, $57 \%$ (24/42) did so by day 3 , and $67 \%$ (28/42) reached maximum depth by day 3 (most because they hit the bottom barrier). It is reasonable to assume that these foundresses would have dug deeper without the constraint of the enclosures. Individuals would typically dig vertically first and branch out in the later days of construction, giving nests a much more vertical orientation than the other species. This species had the least number of nodes relative to nest length, with an intermediate amount of peripheral nodes relative to internal ones and an intermediate average nest degree (Fig. 1; Table 1). Like $P$. salinus, the number of branches grew nearly isometrically with the number of nodes (Fig. 2).

Tunnel length and digging time

Tunnel length also varied significantly across species (KruskalWallis: $\chi^{2}=60.13, d f=2, P<0.001$, post hoc: $P<0.001$ all comparisons, Table 1). Despite their slightly slower rate than $P$. rugosus, $P$. salinus foundresses dug on average the greatest amount of total tunnel length, about $35 \%$ more than $P$. rugosus and $67 \%$ more than P. californicus (Table 1). P. salinus foundresses also dug for significantly more time than the other two species (Kruskal-Wallis: $\chi^{2}=39.34, d f=2, P<0.001$, post hoc: $P<0.001 P$. californicus \& $P$. salinus, $P$. salinus \& $P$. rugosus), averaging $44 \%$ longer than $P$. californicus and $53 \%$ longer than P. rugosus (Table 1).

\section{Digging rates}

Nests of all species grew logistically, with foundresses digging at a decreasing rate over time. This indicated that

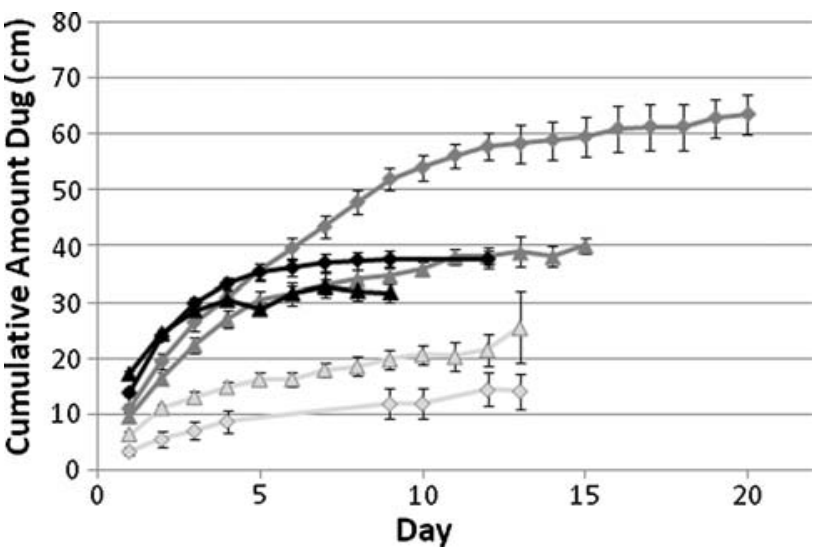

Fig. 3 The mean $( \pm \mathrm{SE})$ cumulative amount dug in relation to days of nest founding. Black $P$. rugosus, dark gray $P$. salinus, light gray $P$. californicus. Diamonds depict 2005/2007 data and triangles depict 2008 data. Foundresses of all species dug at decreasing rates over time, with $P$. salinus digging for the longest amount of time and the greatest tunnel lengths

rate has the largest impact on nest structure at the very beginning of colony initiation (Fig. 3; Table 1). Rates were calculated only for days $0-1,1-2$, and $2-3$ since these periods were when the foundresses dug the most and hence produced the most interesting comparisons. Rates for all three time spans were positively associated with degree of claustrality across species such that on average $P$. rugosus foundresses dug the fastest, followed by $P$. salinus, and $P$. californicus dug the slowest (Kruskal-Wallis, Days 0-1: $\chi^{2}=55.55, d f=2, P<0.001$, post hoc: $P<0.001$ all comparisons; Days 1-2: $\chi^{2}=38.89, d f=2, P<0.001$ post hoc: $P<0.001 P$. californicus \& $P$. salinus, $P$. californicus \& P. rugosus; Days $2-3, \chi^{2}=33.054, d f=2$, $P<0.001$, post hoc: $P<0.001$ P. californicus $\& P$. salinus, $P$. californicus \& P. rugosus, Table 1$)$.

Interestingly, the facultative species ( $P$. salinus) was more similar in some nest characteristics to the claustral species ( $P$. rugosus) than to the semi-claustral species (P. californicus) even though it is closer in size to the latter species. P. rugosus is on average $\sim 70 \%$ larger in mass than $P$. salinus while $P$. salinus is on average only $\sim 3 \%$ larger than $P$. californicus. Yet, $P$. salinus and $P$. rugosus have the most similar digging rates during the first 3 days and $P$. salinus actually dug greater distances in tunnel length and for a greater number of days than the larger $P$. rugosus. $P$. salinus also had more a similar average node degree to $P$. rugosus than to $P$. californicus (see above). Overall, $P$. salinus foundresses appear to be notably active for their size.

Within species, there was a significant negative association of foundress mass with digging rate for days $0-1$ in P. californicus, where variation in mass explained $19 \%$ of the variation in rate (Linear Regression $F=6.89, d f=30$ $P=0.014$ ) and a positive trend in $P$. rugosus. For days 
1-2, $P$. salinus and $P$. rugosus digging rates also showed slight positive trends with mass. Lastly, there was a significant positive association for days $2-3$ in $P$. salinus where variation in mass explained $18 \%$ of the variation in rate (Linear Regression $F=7.50, d f=35, P=0.01$ ) and a slight positive trend in $P$. rugosus.

Nest entrance-plugging behavior

\section{P. californicus}

Ninety-one percent (20/22) of nest entrances were left open during the entirety of nest founding. Foundresses typically stayed near the top of the nest and exited the nest regularly. About 9\% (2/22) of the nest entrances were variable in nest closure, meaning that foundresses opened and closed their nest at least once. Both of these foundresses were above the average mass of the entire sample. None of the nests were closed the entire time.

\section{P. salinus}

The majority of nests, $60.5 \%(23 / 38)$, were left open the entire time of founding while $39.5 \%$ (15/38) of nests were variable in closure. None of the nests were closed the entire time of founding. Foundress mass was not associated with entrance-plugging behavior, as the average mass of foundresses that showed variable behavior $(15.52 \mathrm{mg}$ ) was not notably different the average mass of the entire sample (15.48 mg).

\section{P. rugosus}

Only $4.5 \%$ (2/44) of nest entrances were left open the entire time of nest founding. Foundresses with opened nest entrances stayed inside their nest and no foraging was observed. The majority of nests, $61.4 \%$ (27/44), were closed the entire time of founding and $34.1 \%(15 / 44)$ of nests had variable closure. The average mass of foundresses that showed variable behavior $(46.37 \mathrm{mg}$ ) was not very different from the average of the entire sample $(46.92 \mathrm{mg})$. The foundresses that left their nests open were either at or above average mass of the entire sample.

\section{Discussion}

The architecture of mature nests is diverse in ants and has been described in numerous species (Buhl et al., 2004, 2006; Cassill et al., 2002; Diehl-Fleig and Diehl, 2007; Forti et al., 2007; Mikheyev and Tschinkel, 2004; Rasse and Deneubourg, 2001; Sudd, 1971; Tschinkel, 2004, 2005; Verza et al., 2007; Vieira et al., 2007). Descriptions of the architecture of incipient ant nests, however, are sparse (Fernandez-Marin et al., 2005) but important for understanding nest founding behavior of single foundresses. This study describes differences in incipient nests built by single Pogonomyrmex foundresses that differ in size within species and degrees of claustrality (which is correlated to size) across species. The different structural aspects of the nests across species suggest they have evolved in response to differing abiotic conditions and foraging behaviors (claustral, facultative, or semiclaustral).

Soil quality, particularly its ability to hold water, is a principle abiotic factor in desert systems (Noy-Meir, 1973) and appears to strongly influence harvester ant ranges (Cole, 1968; Johnson 1992, 1998, 2000a, b, 2001, 2006b). Edaphic qualities have been shown to separate harvester ant species in sympatric sites as well as along contact zones in North America (Johnson, 2000a, b). Soil moisture has also been shown to be positively associated with foundress survival, quality, and first brood production in $P$. rugosus and $P$. barbatus (Johnson, 1998). Temperature is another abiotic factor that may considerably influence nest structure. Habitats at higher elevations and latitudes are cooler than those at lower elevations and latitudes. While this study did not directly test founding success across different habitats, different species likely have adapted to their abiotic environments in different ways that are reflected in nest structure.

Nest characteristics are also likely influenced by degree of claustrality of foundresses. Species that differ in claustrality differ in both size and foraging behavior. Size could confer certain advantages as far as physical abilities (e.g., digging rate and tolerance for arid conditions). Foraging behavior could affect nest structure because foundresses must allocate time and energy to this behavior. Energy spent foraging has been suggested to have a minimal cost relative to benefit in workers of $P$. occidentalis (Fewell, 1988), but has been shown to be energetically costly in other species (Fewell et al., 1996). Time could be valuable during founding in that it can be traded off on either nest construction or raising brood (foraging and oviposition). Colonies that get a head start on the latter may have a competitive advantage (Hölldobler and Wilson, 1990; Johnson, 2001; Tschinkel and Howard, 1983), reach reproductive size faster (Vargo, 1988), or be in better condition before a time of dormancy (e.g., winter). Energy and time spent foraging in semi-claustral and facultative species thus may put a constraint on nest construction. Given the constraints of water availability, energy, and time budgets, possible explanations for nest structure across the three study species are discussed below.

The semi-claustral $P$. californicus produced the shallowest and most branched nests with the shortest total 
tunnel length. This species occurs in the far western parts of the lower United States (Cole, 1968) and is a hot desert specialist (Johnson, 2000b). The small body size (and high surface area to volume ratio) of $P$. californicus foundresses together with their hot and sandy habitats suggests that water retention is problematic (Johnson, 2000b). It would seem to be to their advantage to dig deep nests where water retention would be easier. However, foundresses did not dig deep, and may have evolved shallow nest building in order to reserve energy stores for foraging. Since this species has nuptial flights triggered by photoperiod and not rain (Johnson, 2000b), they are likely very well-adapted to arid conditions during founding. Though the relatively large particle size of sand reduces water retention (Johnson, 2006b; Noy-Meir, 1973), sandy soils under certain conditions have been shown to contain water well (i.e., "inverse texture effect," Noy-Meir, 1973), which may be sufficient to keep these foundresses hydrated. Entrance-plugging behavior in this species exhibited the predicted outcome of all the foundresses keeping their nest entrances open. This result is intuitive since foundresses regularly leave the nest to forage during founding and corroborates other descriptions of semi-claustral behavior (Brown and Bonhoeffer, 2003; Johnson, 2002).

The facultative $P$. salinus produced highly branched nests of intermediate depth with the longest tunnel length out of all three species. Interestingly, this species had digging rate, nest depth, and tunnel length that were more similar to the much larger $P$. rugosus than to the slightly smaller $P$. californicus. P. salinus generally lives at higher altitudes (approx. 2,067 m at the study site) and latitudes where it is cooler for much of the daytime (Cole, 1968; Johnson, 2000b) relative to the other two species. The nuptial flights at this locality are triggered by rain and the soil is fine-textured and rocky (Millar, 1996; Enzmann and Nonacs, pers. obs.), both which increase water retention (Johnson, 2006b; Millar, 1996; Nobel et al., 1992). These factors may mean that water availability during founding is not as problematic as it is for the other two species. The substantial shallow branching of these nests may actually serve to foster brood development near the nest surface given the cooler temperatures (Johnson, pers. comm.). This has been observed in mature $P$. salinus nests in mornings, where brood are kept within inches of the surface (Anderson and Munger, 2003; Enzmann and Nonacs, pers. obs.). With regard to nest depth, given that this species is facultative and often must forage (Anderson and Keyel, 2006; Enzmann, unpubl. data), foundresses may only dig nests of intermediate depths in order to save energy for this activity.

The observation that most of $P$. salinus foundresses kept their nests open brings up the question about how much this facultative species actually forages. In this and other studies, foundesses always foraged (Anderson and Keyel, 2006; Enzmann, unpubl. data). Even when $P$. salinus did plug nests, it was not associated with body size or absence of foraging, indicating that it is not associated with more "claustral-like" behavior. Indeed, P. salinus produces very few brood when denied food and is appears to be more closely placed to the "semi-claustral" side of the continuum (Anderson and Keyel, 2006; Enzmann, unpubl. data,). The observation that $P$. salinus usually keeps their nest open further supports that idea that under most natural conditions foundresses probably forage and do not behave claustrally.

The claustral $P$. rugosus, produced very deep nests with little lateral branching. In the western United States, this species is limited to xeric areas with sandy soils (Johnson, 2000a). In more mesic eastern areas (e.g., southeastern Arizona, western Texas and eastern Mexico (Cole, 1968; Johnson, 2000b)), P. rugosus inhabits drier soils with less clay content and is replaced by $P$. barbatus in wetter areas (Johnson, 2000a, b). Their large size (smaller surface area to volume ratio) allows them to retain more water and serves as an explanation for why they live in soils with more sand (Johnson, 2000a, 2001). Yet, foundresses of this species dig the deepest nests, which seems counterintuitive. One explanation may be that since these foundresses do not forage after founding, they can use much of their stored energy to produce deep nests that will further protect from the desiccating conditions. Deep nests may also protect brood from extreme temperatures during the day. In our experience, brood of this species are, at most, rarely brought near the surface (Enzmann and Nonacs, pers. obs).

As expected, this species usually kept nests closed. However, it is notable that a fair percentage of foundresses showed variable nest-plugging behavior and left their nest entrances open even though they were never observed leaving their nest. Clearly, although claustral foundresses typically block entrances and semi-claustral foundresses typically leave nests open, this behavior has some variation that is not clearly explained by just body size or founding strategy.

The results of this study indicate that within-species mass is generally not a good predictor of incipient nest characteristics. Intraspecific associations of body size with digging rate were not present consistently in all species over all time periods. While $78 \%$ (7/9) of the rate versus mass regressions had a positive slope, no robust general conclusions can be made about a positive effect of mass on digging rate. Lack of an association of mass with nest depth within any of the species further supports this conclusion. This finding is especially revealing for the facultative species, $P$. salinus, since one might predict mass to be associated with nest type (similarity to claustral versus semi-claustral nests). Our results run counter to the 
broad generalization that body size within species is a significant factor affecting nest characteristics.

The incipient nests across species are intriguing in a broader biological view because they are characterized by a gamut of qualities, or a syndrome. Syndromes are suites of correlated characteristics that exist as a group rather than distinctive entities. They have been previously described for floral traits that have evolved in response to pollinator characteristics (Fenster et al., 2004), such as Australian nutmeg in response to beetle pollinators (Armstrong and Irvine, 1989), correlated behaviors across contexts (behavioral syndromes) such as in funnel web and fishing spiders, and sticklebacks (Sih et al., 2004), and for migratory characteristics of insects such as the sand cricket (Fairbairn, 1994).

In the case of nest-founding ants, syndromes may exist since several nest characteristics are correlated with each other across the claustrality continuum, such as digging rate, branching abundance, nest depth, and nest-plugging behavior. These correlations may have a variety of explanations. For instance, digging rate may co-vary with nest depth because foundresses may allocate only a certain amount of time to reach a certain nest depth before for they start to oviposit or forage. Branching abundance may covary with nest depth because foundresses that need to forage may have evolved to build shallow, lateral nests than vertical deep ones. This is not to mean that certain characteristics are dependent others, just that different combinations of ecology, energy budgets, and foraging behavior may lead to the evolution of distinctive nest types. Such nest types of "shallow and branched" and "deep and vertical" have been described previously in individual worker ants of several species (Sudd, 1971). More species comparisons would provide greater evidence for characteristic inter-correlated differences in nest initiation.

Future studies could measure the nest initiation characteristics of other species in order to explore whether colony founding syndromes exist across the claustrality continuum. Other studies may further explore the limitations of foundress nest structure, such as manipulating soil type and moisture or temperature during nest initiation (Johnson, 1998). Investigating such parameters might help explain macro- and micro-demographics in Pogonomyrmex. One limiting factor of this study was that structure was analyzed in only two dimensions, which may inaccurately represent tunneling networks. Foundress nest structure could also be measured in three dimensions, as has been done on adult colonies of ants (Tschinkel, 2004, 2005) and termites (Perna et al., 2008). Nest structure of pleometrotic versus haplometrotic foundresses within species (e.g., $P$. californicus) could be investigated to understand the affect of multiple versus single foundresses. Finally, one can use these results to further compare the costs and benefits of different degrees of claustrality across species and/or body size within species and link them to fitness consequences in nature.

Acknowledgments We would like to thank Robert Johnson for his comments and aid (with several graduate students at Arizona State University) in collecting many of the foundresses used in this study. We would also like to thank Smadar Gilboa for her advice on statistical analyses, the Nonacs lab for their comments and assistance, Danielle Parsons for her aid in making nest enclosures, and Justin Ranaan for his help with data collection and analysis. This work involved collecting at the University of California Valentine Eastern Sierra Reserve and was supported by two grants from the University of California Valentine Eastern Sierra Reserve, a Mildred Mathias grant, and a California Desert Research fund grant from the Community Foundation.

Open Access This article is distributed under the terms of the Creative Commons Attribution Noncommercial License which permits any noncommercial use, distribution, and reproduction in any medium, provided the original author(s) and source are credited.

\section{References}

Adam R.A. and Mitchell A.D. 2009. Energetics and development of incipient colonies of the harvester termite, Trinervitermes trinervoides (Sjöstedt) (Termitidae, Nasutitermitinae). Insect. Soc. 56: 21-27

Anderson K.E. and Keyel A.C. 2006. Mating flight, metrosis, and semi-claustrality in the seed-harvester ant Pogonomyrmex salinus (Hymenoptera, Formicidae). Insect. Soc. 53: 92-96

Anderson K.E. and Munger J.C. 2003. Effect of temperature on brood relocation in Pogonomyrmex salinus (Hymenoptera: Formicidae). West N. Am. Naturalist 63: 122-128

Armstrong J.E. and Irvine A.K. 1989. Floral biology of Myristica insipida (Myristicaceae), a distinctive beetle pollination syndrome. Am. J. Bot. 76: 86-94

Brown M.J.F. and Bonhoeffer S. 2003. On the evolution of claustral colony founding in ants. Evol. Ecol. Res. 5: 305-313

Buhl J., Gautrais J., Deneubourg J.L. and Theraulaz G. 2004. Nest excavation in ants: group size effects on the size and structure of tunneling networks. Naturwissenschaften 91: 602-606

Buhl J., Gautrais J., Deneubourg J.L., Kuntz P. and Theraulaz G. 2006. The growth and form of tunnelling networks in ants. J. Theor. Biol. 243: 287-298

Cahan S.H. and Rissing S.W. 2005. Variation in queen size across a behavioral transition zone in the ant Messor pergandei. Insect. Soc. 52: $84-88$

Cassill D., Tschinkel W.R. and Vinson S.B. 2002. Nest complexity, group size and brood rearing in the fire ant, Solenopsis invicta. Insect. Soc. 49: 158-163

Cole A.C. 1968. Pogonomyrmex Harvester Ants: a Study of the Genus in North America. University of Tennessee Press, Provo, Utah. 70,71,106,107,121 pp

Croft D.P., James R. and Krause J. 2008. Exploring Animal Social Networks. Princeton University Press, Princeton. 72-73 pp

Diehl-Fleig E. and Diehl E. 2007. Nest architecture and colony size of the fungus-growing ant Mycetophylax simplex Emery, 1888 (Formicidae, Attini). Insect. Soc. 54: 242-247

Fairbairn D.J. 1994. Wing dimorphism and the migratory syndrome: Correlated traits for migratory tendency in wing dimorphic insects. Res. Popul. Ecol. (Kyoto) 36: 157-163 
Fenster C.B., Armbruster W.S., Wilson P., Dudash M.R. and Thomson J.D. 2004. Pollination syndromes and floral specialization. Annu. Rev. Ecol. Evol. Syst. 35: 375-403

Fernandez-Marin H., Zimmerman J.K., Wcislo W.T. and Rehner S.A. 2005. Colony foundation, nest architecture and demography of a basal fungus-growing ant, Mycocepurus smithii (Hymenoptera, Formicidae). J. Nat. Hist. 39: 1735-1743

Fewell J.H. 1988. Energetic and time costs of foraging in harvester ants, Pogonomyrmex occidentalis. Behav. Ecol. Sociobiol. 22: 401-408

Fewell J.H., Harrison J.F., Lighton J.R.B and Breed R.B. 1996. Foraging energetics of the ant, Paraponera clavata. Oecologia 105: 419-427

Forti L.C., Camargo R.S., Fujihara R.T. and Lopes J.F.S. 2007. The nest architecture of the ant, Pheidole oxyops Forel, 1908 (Hymenoptera, Formicidae). Insect Sci. 14: 437-442

Gordon D.M. and Kulig A.W. 1996. Founding, foraging, and fighting: Colony size and the spatial distribution of harvester ant nests. Ecology 77: 2393-2409

Hölldobler B. and Wilson E.O. 1990. The Ants. Harvard University Press, Cambridge, Massachusetts, $732 \mathrm{pp}$

Johnson R.A. 1992. Soil texture as an influence on the distribution of the desert seed-harvester ants Pogonomyrmex rugosus and Messor pergandei. Oecologia (Berlin) 89: 118-124

Johnson R.A. 1998. Foundress survival and brood production in the desert seed-harvester ants Pogonomyrmex rugosus and $P$. barbatus (Hymenoptera, Formicidae). Insect. Soc. 45: 255-266

Johnson R.A. 2000a. Habitat segregation based on soil texture and body size in the seed-harvester ants Pogonomyrmex rugosus and P. barbatus. Ecol. Entomol. 25: 403-412

Johnson R.A. 2000b. Seed-harvester ants (Hymenoptera: Formicidae) of North America: An overview of ecology and biogeography. Sociobiology 36: 89-122

Johnson R.A. 2001. Biogeography and community structure of North American seed-harvester ants. Annu. Rev. Entomol. 46: 1-29

Johnson R.A. 2002. Semi-claustral colony founding in the seedharvester ant Pogonomyrmex californicus: a comparative analysis of colony founding strategies. Oecologia 132: 60-67

Johnson R.A. 2003. Notes from the Underground, Methods and Madness: culturing queens and colonies from the genus Pogonomyrmex. In: http://www.notesfromunderground.org/archive/ vol101/methods/pogonomyrmex.html

Johnson R.A. 2006a. Capital and income breeding and the evolution of colony founding strategies in ants. Insect. Soc. 53: 316-322

Johnson R.A. 2006b. Biogeographical parallels between plants and ants in North American deserts (Hymenoptera: Formicidae; Spermatophyta). Myrmecol. Nachr. 8: 209-218

Kikuchi T., Higashi S. and Murakami T. 1999. A morphological comparison of alates between monogynous and polygynous colonies of Myrmica kotokui in northernmost Japan. Insect. Soc. 46: $250-255$

McInnes D.A. and Tschinkel W.R. 1995. Queen dimorphism and reproductive strategies in the fire ant Solenopsis geminata (Hymenoptera: Formicidae). Behav. Ecol. Sociobiol. 36: 367375

Mikheyev A.S. and Tschinkel W.R. 2004. Nest architecture of the ant Formica pallidefulva: structure, costs and rules of excavation. Insect. Soc. 51: 30-36

Millar, C.I. 1996. Sierra Nevada Ecosystem Project, Final Report to Congress, vol. I, Assessment Summaries and Management
Strategies (Davis: University of California, Centers for Water and Wildland Resources)

Nobel P.S., Miller P.M. and Graham E.A. 1992. Influence of rocks on soil temperature, soil water potential, and rooting patterns for desert succulents. Oecologia 92: 90-96

Nonacs P. 1990. Size and kinship affect success of co-founding Lasius-pallitarsis queens. Psyche (Cambridge) 97: 217-228

Noy-Meir I. 1973. Desert ecosystems: environment and producers. Annu. Rev. Ecol. Syst. 4: 25-51

Passera L. and Keller L. 1990. Loss of mating flight and shift in the pattern of carbohydrate storage in sexuals of ants (Hymenoptera: Formicidae). J. Comp. Physiol. B Biochem. Syst. Environ. Physiol. 160: 207-212

Perna A., Jost C., Couturier E., Valverde S., Douady S. and Theraulaz G. 2008. The structure of gallery networks in the nests of termite Cubitermes spp. revealed by X-ray tomography. Naturwissenschaften 95: 877-884

Pfennig D.W. 1995. Absence of joint nesting advantage in desert seed harvester ants - evidence from a field experiment. Anim. Behav. 49: $567-575$

Rasse P. and Deneubourg J.L. 2001. Dynamics of nest excavation and nest size regulation of Lasius niger (Hymenoptera: Formicidae). J. Insect Behav. 14: 433-449

Roff D.A. 1992. The Evolution of Life Histories: Theory and Analysis. Chapman \& Hall, New York, 126 pp

Rüppell O. and Heinze J. 1999. Alternative reproductive tactics in females: The case of size polymorphism in winged ant queens. Insect. Soc. 46: 6-17

Rüppell O., Heinze J. and Hölldobler B. 1998. Size-dimorphism in the queens of the North American ant Leptothorax rugatulus (Emery). Insect. Soc. 45: 67-77

Sih A., Bell A. and Johnson C. 2004. Behavioral syndromes: an ecological and evolutionary overview. Trends Ecol. Evol. 19: 372-378

Stearns S.C. 1992. The Evolution of Life Histories. Oxford University Press, Oxford, $145 \mathrm{pp}$

Sudd J.H. 1971. Specific patterns of excavation in isolated ants. Insect. Soc. 17: 253-260

Tschinkel W.R. 2004. The nest architecture of the Florida harvester ant, Pogonomyrmex badius. J. Insect Sci. (Tucson) 4: 1-19

Tschinkel W.R. 2005. The nest architecture of the ant, Camponotus socius. J. Insect Sci. (Tucson) 5: 1-18

Tschinkel W.R. and Howard D.F. 1983. Colony founding by pleometrosis in the fire ant, Solenopsis invicta. Behav. Ecol. Sociobiol. 12: 103-113

Vargo E.L. 1988. Effect of pleometrosis and colony size on the production of sexuals in mongyne colonies of the fire ant Solenopsis invicta. In: Advances in Myrmecology (Trager J.C., Ed), E.J. Brill, Leiden. 220-222 pp

Verza S.S., Forti L.C., Lopes J.F.S. and Hughes W.O.H. 2007. Nest architecture of the leaf-cutting ant Acromyrmex rugosus rugosus. Insect. Soc. 54: 303-309

Vieira A.S., Antonialli-Junior W.F. and Fernandes W.D. 2007. Nest architecture of the ant Ectatomma vizottoi Almeida (Hymenoptera, Formicidae). Rev. Bras. Entomol. 51: 489-493

Wheeler D.E. and Buck N.A. 1996. Depletion of reserves in ant queens during claustral colony founding. Insect. Soc. 43: 297-302

Wiernasz D.C. and Cole B.J. 2003. Queen size mediates queen survival and colony fitness in harvester ants. Evolution 57: 21792183 